\title{
DECISION SUPPORT TOOL FOR HYGIENIC PRODUCT COMPANY INDUSTRIAL TACTILE SENSORY PANEL ANALYSIS IMPLEMENTATION
}

\author{
Rahma TILOUCHE ${ }^{1}$, Soumaya SAYEB ${ }^{1}$, Naima HALLAB ${ }^{1}$, Mohamed BEN HASSEN ${ }^{2-1}$ \\ ${ }^{1}$ Textile Engineering Laboratory, Monastir University, Monastir, Tunisia \\ ${ }^{2}$ College of Engineering: Industrial Engineering Department, Taibah University Saudi Arabia,
}

Received: 22.12 .2017

Accepted: 28.06 .2018

\begin{abstract}
In the last few years, there has been a growing interest in hygienic product, and particularly in baby diaper. Those products are very complex structures, they are mostly constituted from wood pulp, superabsorbent material, and polymer derived nonwoven materials. This can engender a difficult assessment of comfort parameter and specifically the touch. The main goal of this work is dedicated to nonwoven fabric hand touch analysis and the formation of a group of professional testers to provide the required product quality check. In fact, this study is conducted in collaboration with an industrial partner. The creation of professional testers for the assessment of hygienic product can be a valuable tool to predict consumers' needs and satisfaction. The remainder of this paper is organized into four section: section I describes the sample preparation environment, which involves test room and assessment booth. Section II outlines the recruitment of five panelist after an interview and a selection test. Section III is devoted to the descriptors selection; that is, the selection of a set of terms required for properly identifying the non-woven fabric to be used in the hygienic product. This involves both qualitative and quantitative filtration. This filtration leads to shortlisting the descriptors and assessment techniques. Section III describes the first training sessions of panelists. Lastly, section four summarizes the final list of attributes and assessment techniques and adopted references for each selected descriptor.
\end{abstract}

Keywords: Hand touch; sensory analysis; hygienic product; panel; nonwoven structures; descriptors, subjects, decision tool.

Corresponding Author: Mohamed Ben Hassen e-mail: m.benhassen@taibahu.edu.sa; benrayen@yahoo.fr / DOI: 10.32710/tekstilvekonfeksiyon.493093

\section{Introduction}

The sense of touch is a rich sense, which involves different mechanisms and covers different stimuli of sensitivity. The physicochemical properties of hygiene products are directly related to consumer perception (touch, surface geometry...) [1].In fact, when used, they are in a direct contact with skin that triggers the sense of touch that causes either comfort or discomfort of the user. In the last few years there has been a growing interest in sensory analyses since they allow customer comfort feeling prediction in order to meet his/her expectation. Besides, they are considered as a valuable quality check and assessment in the company, between manufacturer, suppliers and project stakeholders. In fact, Sensory analysis enter into the product design process validation by integrating customer expectations in the decision [2]. Different devices can evaluate objectively this sense such as KAWABATA, FAST... In addition, personals called "panelists" can evaluate it subjectively. This is expected and not unusual as the quality perception is subjective and differ from one to another. After training panelist measuring consistently like instruments, the stimulation will follow an objective phenomenon [3]. The "NF ISO 5492" standard defines sensory analysis as "the examination of the organoleptic properties of a product by the sense of organs" [4]. Tactile sensory analysis is hugely related to the human comfort; comfort studying have always been interesting subject for researchers as well as industrialists. In fact, clothing comfort is defined as "the tactile sensations felt by a human through the mechanical interactions between the body and the garment" [5] [6].

Among many products in textile industry, the personal care related products are in perpetual development and in high demand. That is why performance of hygienic product extremely varies in consequence [7]. The literature on textile sensory analysis shows a variety of approaches in this field.

A group of researchers studied the hand touch sensitivity of commercially produced nonwovens for sanitary and medical uses in dry and wet conditions. They found that the handling (softness and smoothness) of diapers is correlated to both diaper dermatitis and wearing comfort [8].

In other study the wetness perception of a commercially pant liners was investigated by making an objective evaluation based on physical properties and a subjective evaluation based on hand evaluation tests and wear trials. They found a correlation between the hand touch sensing 
and the maximum value of heat flow under the wet condition. They considered it one of the key parameters for estimating the wetness and comfort of hygiene products [9].

Hallab N. \& [10] have developed a sensory assessment method for preparing and training candidates to be experts in measuring the level of comfort upon hand tough sensing of woven fabrics.. They were able to train a panel experts, that are able to carry out a sensory profile of 16 attributes, within a very small standard deviation, to describe the tactile quality of woven fabrics.

Most of the previous studies do not take into account nonwoven fabric hand touch whether they are woven fabric or knitted fabric [12]. Our partner company is convinced by the importance of integrating the sensory aspect in the design of the hygienic product and/or the manufacturing process.

Therefore, an internal sensory were developed following a standardized scheme. The main goal is to develop a group of experts in order to judge the compatibility of hygienic products to different hand profiles (thin, rough, smooth, soft, etc). Another goal was to develop gestures and procedures for tactile perception specifically approved for these typical products. Sensory evaluation of this work will be presented in a further work. Our attention were limited in this first part to the basic steps to create a tactile sensory panel.

Our instigation were started by establishing the working environment: that involves test room and assessment booth. Subsequently, five panelists were recruited that underwent an interview and a selection test. The descriptors selection came next by choosing the terms which describe the required properties of non-woven targeted for hygienic products. The drive of the whole work is the descriptors generation and selection. Therefore, three different methods were used (online survey, brainstorming and group generation). Lastly, a qualitative and quantitative filtration was realized in order to obtain the short list of descriptors. This allowed us the launch of the subjects training, and finally the creation of a manual guide of procedures and tactile frame reference.

\section{MATERIAL AND METHOD}

\subsection{Panelists selection}

Referring to the norm "ISO NF 13300", a sensory panel should not be composed of less than 5 subjects, it is also advisable to train a number of candidates from two to three times more than the minimum required [12]. This gives a better statistical permanence of the group and ensures correct approach to sensory analysis. Selected subjects are identified in the company by the R\&D department. The advantage of such panel is its confidentiality, their knowledge for different products and consumer needs. Table 1 lists five persons selected from ten people after an interview and a selection test according to their competency, commitment and scientific level. The obtained panel is composed of $10 \%$ of women and $90 \%$ of men with an age ranging between 29 and 35 years old.

Table 1. Panel subjects final list.

\begin{tabular}{|c|l|l|}
\hline Code & Gender & \multicolumn{1}{c|}{ Position } \\
\hline P001 & Man & Laboratory. Tech (R \& D) \\
P002 & Women & Resp. Laboratory (R \& D) \\
P003 & Man & Laboratory. Tech (R \& D) \\
P004 & Man & Laboratory. Tech (R \& D) \\
P005 & Man & Laboratory. Tech (R \& D) \\
\hline
\end{tabular}

\subsection{Training conditions: test room and assessment booth}

Regulations of different standards that are instructive for tactile sensory analysis including the establishment of booths and test room conditions have been followed.

Test room: According to the norm "NF EN ISO139" tests should be done under standardized conditions with a temperature $\mathrm{T}\left({ }^{\circ} \mathrm{C}\right)=20^{\circ} \mathrm{C}$ and a relative humidity $\mathrm{RH}(\%)=$ $65 \%$ [13]. For reliable conditions of sensory analyzes, an isolated environment must be ensured to avoid any kind of distraction and noise. The room should be free of noise and regular lighting is essential.

Assessment booth: Unlike the wood made simple boxes used for this kind of tests for textile industry in Tunisia. According the guidelines of "NF ISO 8589" a specific booth were set-up inspired from commercial booths [14]. A retractable portion in the front side was also added, that allows both blind and visual analysis (color). Figure 1 shows the booth conception installed in a separate conditioned room in the $R \& D$ department in the company.

\subsection{Sample preparation}

The purpose of the establishment of the hand touch panel is to create panelists who can assess hygienic products. For the flexibility of these trained personals, a variety of nonwoven were used: paper towel, topsheet, acquisition layer... For a better understanding of the descriptors, it is more efficient to also work with other structure like knitted fabric with a variability of treatment. The transition of these descriptors to non-woven products can be readily done. Table 2 summarizes the selected samples for training sessions. The training samples have dimensions of $20 \mathrm{~cm}$ by $30 \mathrm{~cm}$ and they must pass through a controlled environment $\left(\mathrm{T}=20^{\circ} \mathrm{C}, \mathrm{RH}=65 \%\right)$ for 24 hours before each sensory evaluation.

Table 2. List of samples used for Training sessions

\begin{tabular}{|l|l|l|l|}
\hline \multicolumn{1}{|c|}{ Code } & \multicolumn{1}{|c|}{ Fabric } & \multicolumn{1}{c|}{ Fiber } & \multicolumn{1}{c|}{ Type } \\
\hline F001 & Non-woven & $100 \%$ Polyester & Acquisition layer \\
\hline F002 & Non-woven & $100 \%$ Viscose & Paper towel embossed \\
\hline F003 & Non-woven & $100 \%$ Polypropylene & Topsheet \\
\hline F004 & Non-woven & $50 \%$ Polypropylene $/ 50 \%$ PE & Double sided (Side loop) \\
\hline F005 & Non-woven & $50 \%$ Polypropylene /50 \%PE & Jersey Fleece \\
\hline F006 & Knitted & $60 \%$ cotton $40 \%$ Polyester & Cross linked \\
\hline F007 & Knitted/Foam & PA/Foam & Leather effect \\
\hline F008 & Knitted coated & $100 \%$ Polyamide & \\
\hline
\end{tabular}



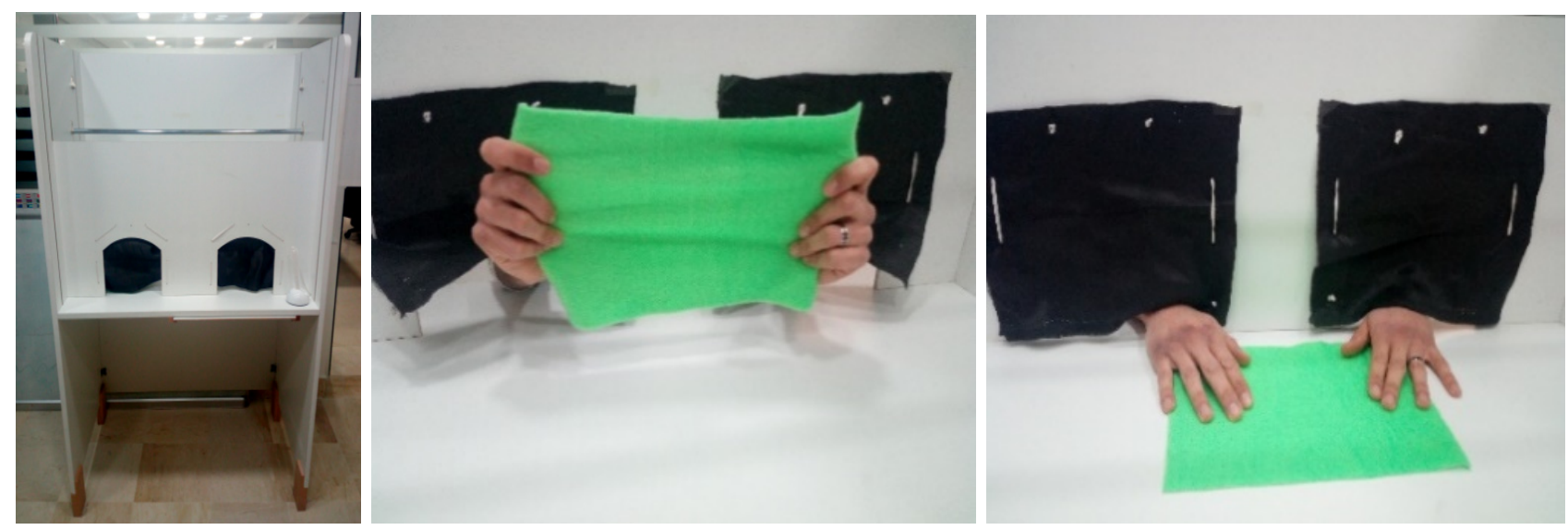

Figure 1: Developed assessment booth (sample and hand position from the back of the booth: animator side).

\section{RESULTS AND DISCUSSION}

\subsection{Descriptors generation}

Descriptors generation is considered as a promising growth axis for a credible sensory evaluation; it will particularly influence the quality of the description of the perceived product.

Guidelines of the "ISO 13299" standard", were referenced in order to describe the sensory properties of a sample according to their perceptions with assigning an intensity value for each property [15]. In a preliminary phase, the choice of appropriate descriptors represents a primary objective because it influences the quality of the sensory analysis. Descriptors must be relevant, discriminating, accurate, comprehensive and independent. As a result, the language established for the product description must be simple to use and easy to understand by all panel members. This terminology should also be large enough to include all the features encountered.

The perceived sensory quality in the touch analysis of hygiene non-woven products is proved to be more complex. Consequently, in order to generate descriptors, three methods were combined respectively: the on line survey, brainstorming and descriptor generation in presence of the product.

Descriptors generation through the on line survey: Purchase Decision for hygienic product (in the absence of product);

\section{Phase 1: Generation and collection of terms}

A survey was broadcasted online to generate tactile descriptors. A sample of three hundred eighty five people including members of the panel were interrogated. The population is quite varied with an age range from 23 years to 56 years constituting $45 \%$ male and $55 \%$ female. Through this survey, everyone is asked to respond on three principal questions. In order to have perspective in their hygienic consumption background, then describe the hygienic product (touch vocabulary) and finally grade the product from 0 to 10 . This survey was able to generate 60 terms (after excluding the repeated terms). At this level, they are not called yet descriptors as the criteria's: relevance, accuracy, completeness and discrimination are not respected. Therefore, a qualitative screening is necessary.

\section{Phase 2: Primary qualitative screening}

A qualitative preliminary screening has eliminated the irrelevant terms and hedonic terms such good, though... Finally, the terms that describes the product package or have meaning other than the tactile sense such as clean, compact, clear, irritating have been removed from the list.

Likewise, terms related to tactile sense but having a similar meaning, were also removed in order to avoid the conflict of understanding of terms later like: fine and thin; flexible and supple; rigid and hard. Finally, a list of 28 words were retained related to tactile sense. (Table 3 )

Table 3. Online survey final list.

\begin{tabular}{|l|l|l|}
\hline Warm & Slight & Thin \\
\hline Sticky & Flexible & Wet \\
\hline Soft & Cold & fatty \\
\hline Elastic & sliding & Moist \\
\hline Thick & Grainy & Heavy \\
\hline Soaked & Adherent & Stiff \\
\hline Silky & Extensible & Relief \\
\hline Smooth & Dry & Uniform \\
\hline Grooved & Rigid & Scratchy \\
\hline Thin & Supple & Hard \\
\hline
\end{tabular}

\section{Descriptors generation through the brainstorming with} the panel (Group decision in the absence of the product);

The Brainstorming technique allows finding the maximum of ideas in the shortest time with deferred judgment [16]. The importance of this step is based on the technical knowledge and the problems faced by the panel on the industrial scale. A free choice method was adopted by leaving each subject choosing and using its own descriptors for the product, in the final profile [17].

\section{Phase 1: Generation of terms}

In order to enhance the participation of all panel members, time was equitably divided to speak comfortably [18]. The panelists were able to generate 16 words. 
Table 4. Final terms selected after discussion.

\begin{tabular}{|l|ll|l|l|}
\hline Descriptors & $\mathbf{I}(\%)$ & $\mathbf{F}(\%)$ & $\mathbf{M}(\%)$ & Class \\
\hline Soft & 85,71 & 100 & 92.58 & 1 \\
Rough & 80 & 100 & 89.44 & 2 \\
Dry & 77,14 & 100 & 87.83 & 3 \\
Elastic & 71,43 & 100 & 84.52 & 4 \\
Grooved & 65,71 & 100 & 81.06 & 5 \\
Granular & 62,86 & 100 & 79.28 & 6 \\
Fatty & 51,43 & 100 & 73.68 & 7 \\
Sticky & 54,29 & 100 & 71.71 & 8 \\
catchy & 8,57 & 28,57 & 15.65 & 9 \\
Pulled & 5,71 & 14,29 & 9.04 & 10 \\
\hline
\end{tabular}

\section{Phase2: Terms regrouping and filtration}

Even after mentioning the priority of the tactile terms generation, the group engendered "false good terms", which are related to the visual sense and structure. Results shows that only $62.5 \%$ of the generated terms will be selected which are related to the tactile sense. However, $37.5 \%$ of terms will be rejected;

\section{Phase3: Screening and Classification}

Terms were grouped according to how strongly they are associated with a tactile character. Each panelist will assign a rating on a scale from 0 to 5 . The geometric mean " $\mathrm{M}$ " is calculated according to equation 1 , which represents the square root of the product of the citation frequency $\mathrm{F}$ by the relative intensity I of each descriptor [17].

\section{$\mathrm{M}=\sqrt{\mathrm{F} * \mathrm{I}} \quad$ Equation 1}

Where:

F: The frequency of the quotation, i.e. the ratio of the number of the attribute quotations to the total number of possible quotations for the attribute.

I: The relative intensity which is the ratio of the sum of the intensities given by all the members of the jury for an attribute to the sum of possible maximum intensities for this attribute.

Descriptors are classified in descending order according to the importance of their geometric mean and are given in. Eight descriptors have greater than $50 \%$ geometric mean. Soft and rough have the most important mean. Catchy and pulled descriptors have the lowest average respectively $(15.65 \%)$ and $(9.04 \%)$, so they are systematically eliminated from the list of descriptors.

\section{Descriptors generation through a group of individuals:} (Consensus in the presence of the product).

In contrast to the survey broadcasted online, this generation is gathering the consumer descriptions in the presence of the product [20]. A group of 15 women were selected with an age range varying from 22 to 35 years old. The group uses mainly: feminine napkins, baby diapers, wipes, toilet paper, facial tissue and napkin.

Women are taken in their life context, so individual background and how she is fitting into their respective entourage have been taken into consideration ... As a result, they are asked to respond according to their experiences: personal, family as well as professional (if any).

\section{Phase 1: Explanation and generation of terms}

The appointed group of women are gathered around a table on which twenty hygienic products were arranged (baby diaper, feminine napkins, panty, diaper, bed liners, wipes ...). The group had the right to choose and manipulate the entire product range without exception. There is no enforcing rule on them; women observe and manipulate the hygiene product according to their choice and note all the terms that come to mind. This phase generates 42 terms, for that a preliminary screening is essential.

\section{Phase 2: Preliminary screening}

A preliminary sorting is conducted and a discussion in conjunction with the group is launched. According to their tactile character, eighteen words was retained and they are listed in.

Table 5. Final list of descriptors selected after discussion.

\begin{tabular}{|l|l|l|}
\hline Soft & Elastic & Tender \\
\hline Steep & Rigid & Sticky \\
\hline Mince & Deformable & Heavy \\
\hline Cold & Rough & Slick \\
\hline Wet & Dry & Thick \\
\hline Silky & Fluffy & Relief \\
\hline
\end{tabular}

\subsection{Preliminary qualitative sorting of descriptors generated by the three methods}

This first sorting is based on the guidelines of "ISO 11035 1995" standard [17]. It is based on the three preliminary sub-lists collected in previous steps. Collected terms from the three lists were grouped to finally retain 20 descriptors summarized in.Excluding the terms that are repeated or having the same meaning like grooved and relief. In this list bipolar terms also called antagonistic also appear, such as; rigid-supple, thick-thin, cold-warm, humid-dry and uniformgrooved.

Table 6. Final list of retained descriptors.

\begin{tabular}{|l|l|l|l|}
\hline Slippery & Sticking & Rigid & Thick \\
\hline Granular & Soft /tender & Supple & Thin \\
\hline Elastic & Silky & Uniform & Grooved \\
\hline Adherent & Fatty & warm & Dry \\
\hline Smooth & Rough & Cold & Humid \\
\hline
\end{tabular}




\subsection{First reducing of the number of descriptors}

The geometric mean, denoted " $M$ ", is calculated. Five descriptors have a geometric mean greater than $50 \%$. Respectively: uniform, supple, dry, soft and thin have the most important geometric means. The descriptors adherent, rigid, granular and fatty have the lowest averages. The attributes adherent $(7.25 \%)$ and granular $(13.78 \%)$ will be systematically removed from the list. However, rigid terms have not been eliminated since they are considered as an antagonist of the flexible term. Some panelists have an ambiguity to use this term, they judge that almost the fabrics either they are supple or they are too supple. That is to say, they did not find samples rigid.

\subsection{Second reducing descriptors}

Principal Component Analysis and the consensual discussion were used respectively for the second reduction.

\section{Principal Component Analysis (PCA)}

PCA is a dimension-reduction tool that can be used in order to decrease a large set of variables to a small set, while preserving most of the information in the large set. This analysis consists of a second reduction by grouping of the identical attributes (positively correlated) or antonyms (negatively correlated). In addition, the analysis involves elimination of some descriptors, that contribute slightly for highlighting differences between the fabrics tested in the sensory profile. In order not to draw unreasonable conclusions in a standardized ACP analysis, it is essential to respect two rules:

- Rule 1: Never take into consideration axes whose eigenvalues are less than one,

- Rule 2: Do not stop between two axes whose eigenvalues are very close. In order to apply this rule it is advisable to draw the eigenvalues histogram and to stop only when a stall between two successive values is distinguished.

The correlation circles and eigenvalues histogram were represented simultaneously on the XLSTAT ${ }^{\circledR}$ software. By applying the two rules mentioned above, results shows $56.81 \%$ of the information gathered in dimension 2 are on the first two axes F1 and F2. To describe $83.90 \%$ of the total information, it suffices to represent the circles of correlations in dimension 5, i.e., to draw the axes F1, F2, F3, F4 and F5 that have significant eigenvalues greater than the threshold equal to one. (Figure 2). In fact, the eigenvalues measure the amount of variation in the total sample accounted by each factor.

The PCA method is very useful in our case of sensory analysis, for the reason that the variables (descriptors) within the data set are highly correlated. In fact, this correlation designates that there is some redundancy in the input information. PCA is used in order to reduce this redundancy. As a result, a smaller number of new variables called principal components will be obtained. Those latter explain most of information in the original variables. The main goal is to:

- $\quad$ Make the variables comparable in order to simplify sensory analysis to the panel ;

- Group together positively correlated variables ;

- Position on opposite sides of the plot origin negatively correlated variables.

It can be seen that, these circles of correlation permitted highlighting the antagonistic terms. In fact, a significant negative correlation between dry-humid, thick-thin, uniformgrooved, and supple-rigid were observed.

Table 7. Attributes classification.

\begin{tabular}{|l|l|l|l|l|l|}
\hline $\mathbf{N}^{\circ}$ & Attributes & $\mathbf{F ~ ( \% )}$ & $\mathbf{I}(\mathbf{\%})$ & $\mathbf{M} \mathbf{( \% )}$ & Class \\
\hline $\mathbf{1}$ & Uniform & 95,00 & 74,00 & 76,44 & 1 \\
$\mathbf{2}$ & Supple & 90,00 & 64,25 & 70,20 & 2 \\
$\mathbf{3}$ & Dry & 77,50 & 59,25 & 61,47 & 3 \\
$\mathbf{4}$ & Soft & 75,00 & 51,25 & 56,62 & 4 \\
$\mathbf{5}$ & Thin & 75,00 & 43,00 & 52,68 & 5 \\
$\mathbf{6}$ & Tender & 75,00 & 40,25 & 48,80 & 6 \\
$\mathbf{7}$ & Thick & 72,50 & 34,50 & 47,79 & 8 \\
$\mathbf{8}$ & Smooth & 60,00 & 41,75 & 43,30 & 9 \\
$\mathbf{9}$ & Slippery & 55,00 & 42,00 & 41,62 & 10 \\
$\mathbf{1 0}$ & Silky & 55,00 & 36,50 & 39,24 & 11 \\
$\mathbf{1 1}$ & Cold & 42,50 & 31,50 & 30,92 & 12 \\
$\mathbf{1 2}$ & Rough & 37,50 & 18,50 & 26,34 & 13 \\
$\mathbf{1 3}$ & warm & 30,00 & 22,75 & 26,12 & 14 \\
$\mathbf{1 4}$ & Elastic & 42,50 & 14,75 & 25,04 & 15 \\
$\mathbf{1 5}$ & Grooved & 35,00 & 16,50 & 24,03 & 16 \\
$\mathbf{1 6}$ & Humid & 25,00 & 17,50 & 20,92 & 17 \\
$\mathbf{1 7}$ & Sticking & 37,50 & 15,75 & 20,08 & 18 \\
$\mathbf{1 8}$ & Fatty & 30,00 & 11,00 & 18,17 & 19 \\
$\mathbf{1 9}$ & Granular & 17,50 & 12,25 & 14,64 & 20 \\
$\mathbf{2 0}$ & Rigid & 20,00 & 9,50 & 13,78 & 21 \\
$\mathbf{2 1}$ & Adherent & 15,00 & 3,50 & 7,25 & \\
\hline
\end{tabular}




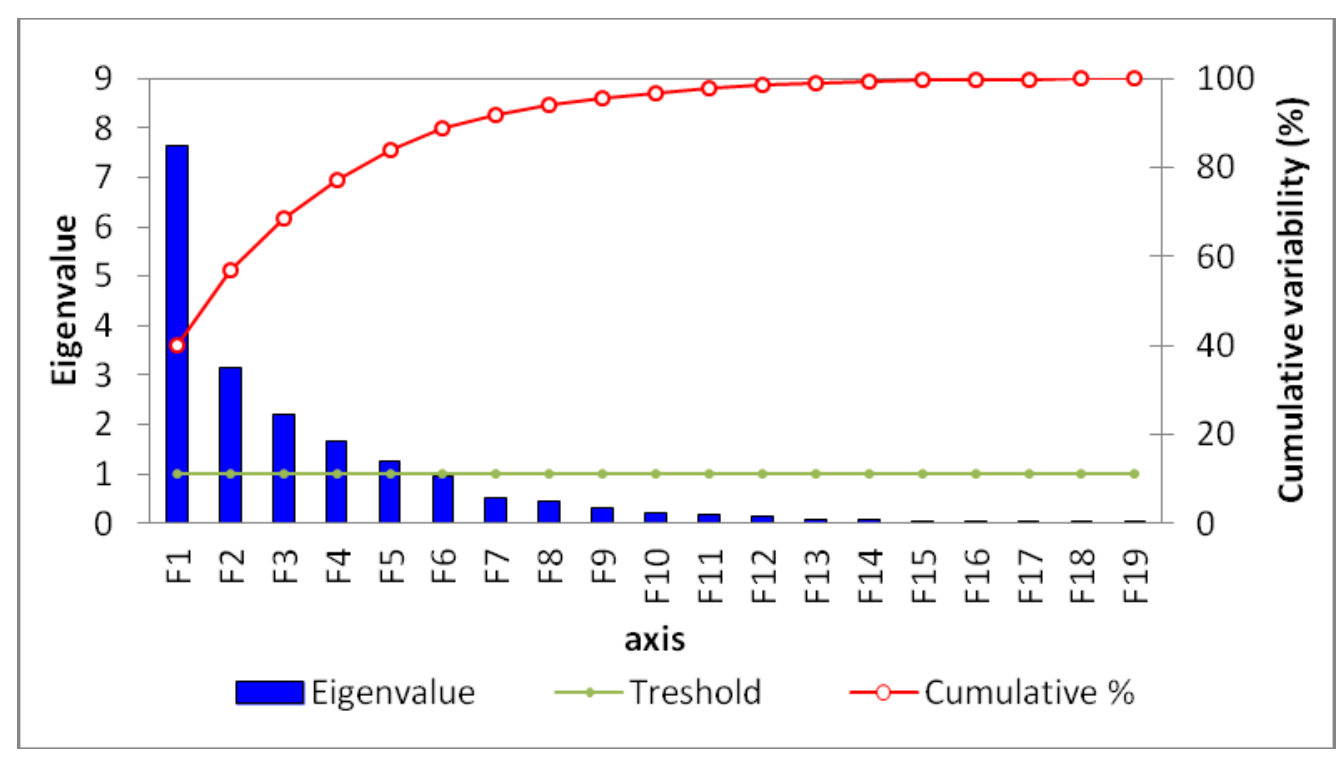

Figure 2 : Eigenvalues histogram for Information variability for the first introductory session.

This is obvious especially for the circle of axes F1, F2 and F3 represented on Figure 3 (a) and (b). Nevertheless, there is a less negative correlation between dry-humid and warmcold, despite the fact that these descriptors are antagonistic. This observation can be explained by a misinterpretation by the panelists. In addition, a significant negative correlation between rough, soft and tender is noticed. An increase in the roughness causes a decrease of soft and tender values. This is influences disagreeably the comfort touch perception. However, a strong positive correlation between soft, tender and uniform were noted. The rise of surface uniformity, gives a better perception of tenderness and softness. Besides, descriptors: slippery, smooth and silky are near to the center and have a less significant effect on sensory profile of tested samples. Descriptors sticky, fat, humid and cold are positively correlated, which means that the increase of fatty and sticky sensation increases subsequently it humid feeling.

According to figure 4, the axis F5 highlights elastic descriptor. These correlation circles also show a significant positive correlation between descriptors soft and silky, and descriptors slippery and smooth. At this level, this positive correlation will not be considered because, from the point of view of definition, these descriptors are different, so some panelists might have been perplexed and confused by them. As a result, only the antagonistic descriptors will be considered (Figure 4(a) and (b)).
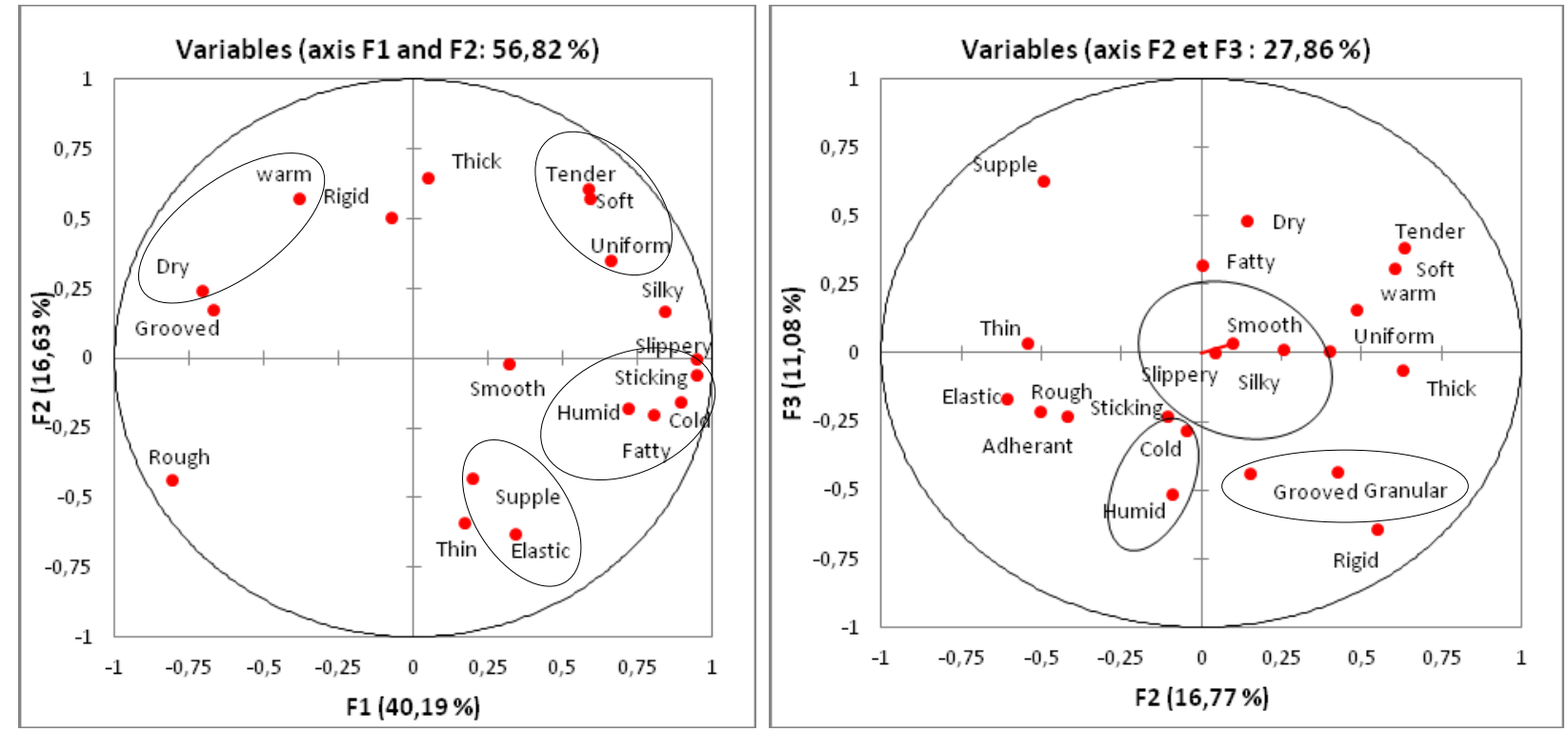

Figure 3. (a) Correlation circles for axis F1-F2. (b) Correlation circles for axis F2-F3. 

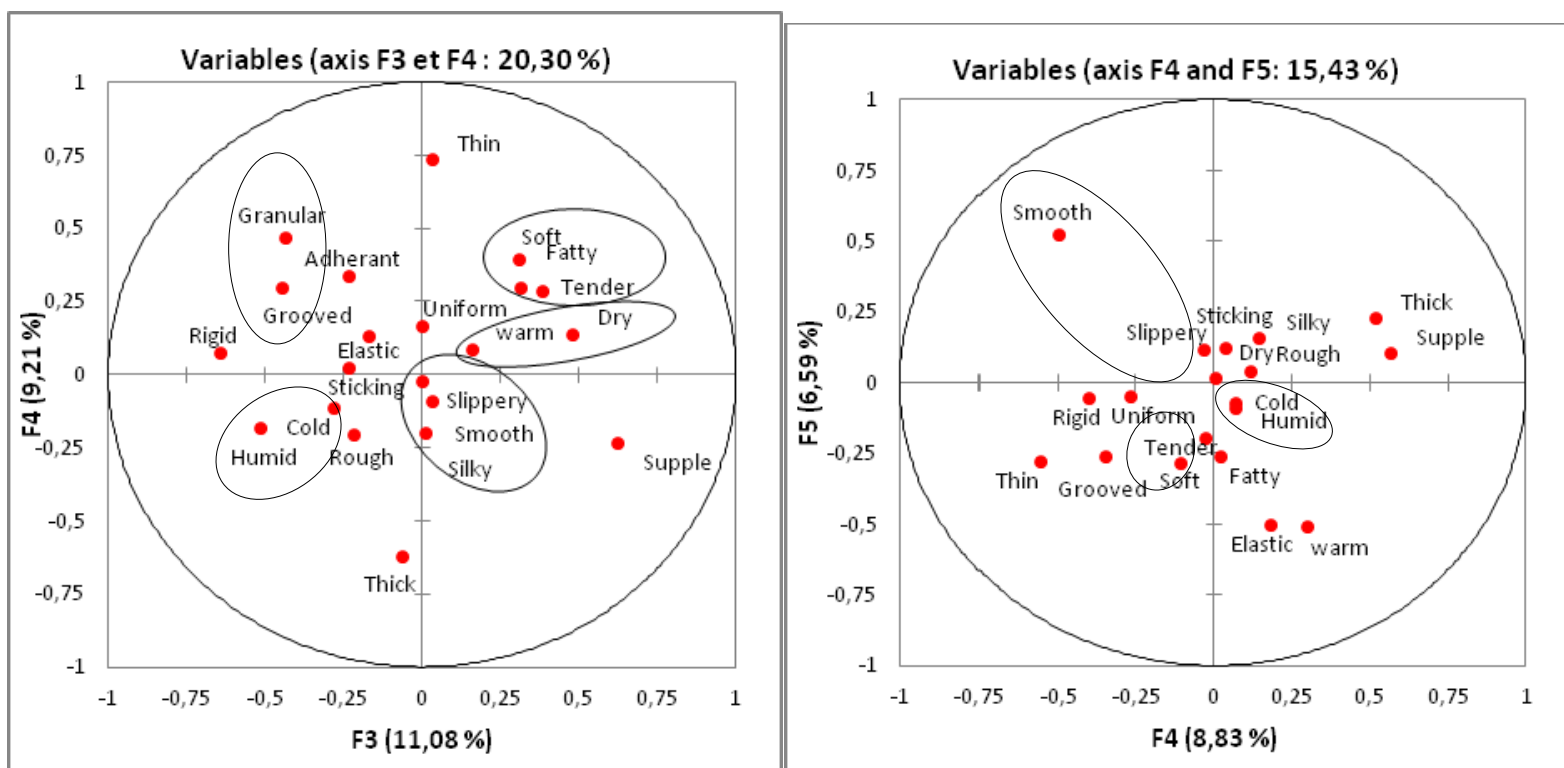

Figure 4. (a) Correlation circles for axis F3-F4. (b) Correlation circles for axis F4-F5.

\section{Reduction by consensual discussion}

The consensual method is very beneficial because it highlights the debate between panel members [21]. During two sessions, the reduction is done through compromising the previous statistical analyzes and upon discussion by consensus principle. The main goal is to find the most relevant descriptors of the list. In addition, for each selected descriptor a very precise definition and the assessment technique were given. During the discussion, it have been found that the descriptors: flexible, rigid, elastic, slippery, smooth, silky, soft, sticky, adhering, granular define a family of very similar sensations. Therefore, the panel found some difficulty in dissimilating the close meaning descriptors. As a result, only the relevant attributes will be kept.

As an example, the panel finds a certain ambiguity in terms supple, rigid and elastic. In order to avoid the multidimensional character of the attributes and - after discussion. The panel suggests that a supple fabric is characterized by the fluency of deformation, while an elastic product is characterized by the fluency of recovering its initial shape. Therefore, both supple and elastic are retained. The attribute "rigid" is removed. Also, Smooth and slippery were eliminated because of their very close definition, as they define a homogeneous and refined surface. The panel decided to retain the silky term as a descriptor designating the product as soft, smooth and slippery at the same time. The granular terms have been removed based on the PCA analysis. Since they are confused with the grooved term. Likewise, the importance of setting up a scale for notations were discussed: where zero denotes an absence of perception for the property considered. The panelist must take all what is discussed above into account to avoid rating the same sensation and its antonym, which can create a contradiction in the sensory profile.

\subsection{Obtaining of the short list of attributes and assessment techniques}

The tactile descriptors selected were classified according to the type of touch in three categories following the techniques described by Hallab N. \& al and according to the type of the gestures exercised as given in the procedures described by Lefebvre A. [21] [10]
The reduced list of 14 descriptors is presented in Hata! Başvuru kaynağı bulunamadı. where the descriptors are classified according to:

Sh: Surface handle: group of attributes that characterizes the properties of the textile fabric surface.

Ph: Physical handle: group of attributes that characterizes the physical properties of the textile fabric.

Dh: Dynamic handle which characterizes the dynamic properties of the textile fabric, and which requires the application of a slight force on the fabric.

Tm: Tangential movement: for the evaluation of the texture: the fingers move rapidly on both sides of the surface.

Om: Orthogonal movement: for the evaluation of pressure, hardness: the fingers apply pressure to one local part of the object.

Sm: Static motion: for the evaluation of the temperature: the hand rests on a part of the object without particular movement.

For each retained descriptor, a specific definition and a preliminary assessment method were fixed. Moreover, an adapted reference fabric was associated (negative and positive) which is used as memory trigger during panel training to make defining the perception intensity easier.

\section{Training of using the scale and the determination of the} tactile perception

The main goal of these first training sessions is to provide the panelists with knowledge techniques of sensory analysis and to develop their abilities to detect and describe sensory stimuli. Before the start of the training program, a form is distributed to the candidates describing the concept of the scale of quotation. The scale used for the notation is from 0 to 10. During the first session, all the panelists are requested to evaluate only two samples for all the attributes according to the assessment method indicated. Training started only by two samples for ensuring panelists were focused on the assessment method. To study the evaluation of the attributes by the panelist. A box plot is represented as the mean value of obtained results for the first sessions. 
Table 8. Final list of attributes.

\begin{tabular}{|c|c|c|c|c|c|c|c|c|c|}
\hline & \multirow{2}{*}{ Attributes } & \multicolumn{3}{|c|}{ Touch category } & \multicolumn{3}{|c|}{ Movement } & \multicolumn{2}{|c|}{ References } \\
\hline & & $\mathrm{Sh}^{*}$ & $\mathbf{P h}^{*}$ & $\mathrm{Dh}^{*}$ & $\mathrm{Tm}^{*}$ & Om* & $\mathrm{Sm}^{*}$ & Negative & Positive \\
\hline \multirow{4}{*}{ Bipolar } & Thermal: cold-warm & * & & & & & * & Leather & wool \\
\hline & Humidity : humid-dry & * & & & & & * & wipe & wool \\
\hline & Thickness : thin-thick & & * & & & & & Topsheet & Foam fabric \\
\hline & Texture : uniform-grooved & ${ }^{*}$ & & & * & & & Paper & Paper toil \\
\hline \multirow{6}{*}{ Simple } & Elastic & & & * & & * & & Paper & Lycra facbric \\
\hline & Soft & * & & & * & & & Topsheet & Kashmir \\
\hline & Silky & * & & & * & & & Raw twill & Silk satin \\
\hline & Sticky & * & & & * & & & Paper & Greasy wipe \\
\hline & Suppleness & * & & & * & & & *** & topsheet \\
\hline & Rough & & & * & & & & $* * *$ & High loft \\
\hline \multicolumn{2}{|r|}{ Physical handle } & $\begin{array}{l}\text { Dh: } \\
\text { Tm: }\end{array}$ & & $\begin{array}{l}\text { namic } \\
\text { ngenti }\end{array}$ & mover & & $\begin{array}{l}\text { Om: } \\
\text { Sm: }\end{array}$ & \multicolumn{2}{|c|}{$\begin{array}{l}\text { Orthogonal movement } \\
\text { Static motion }\end{array}$} \\
\hline
\end{tabular}
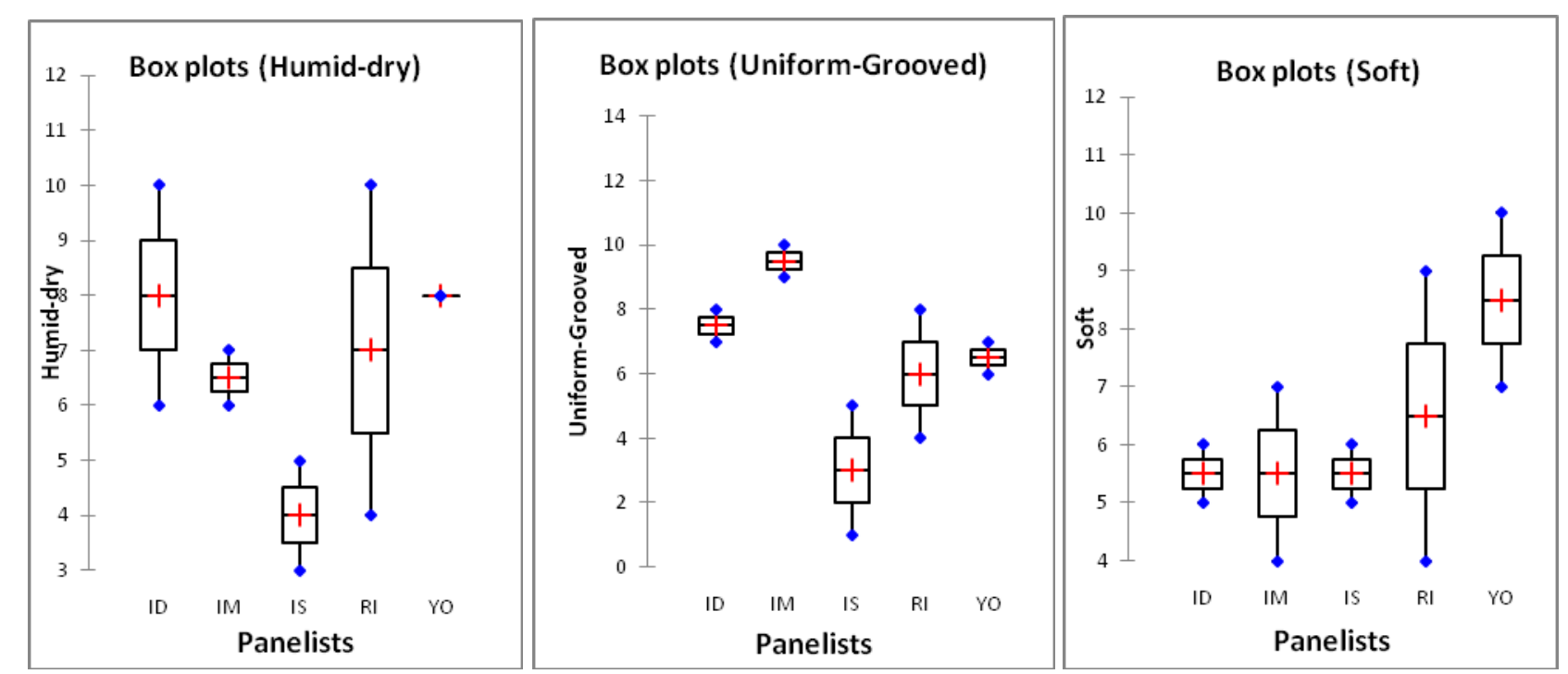

Figure 5 : Example of Box plot for: Soft, uniform-grooved, humid-dry attributes.

For the first session, it was logical to obtain so muchdispersed notes and to have dissensions between panelists since they do not have experience in tactile sensory analysis. The study of the box plot showed that the notes are very dispersed for the terms: soft, uniform-grooved, humid-dry, silky, humid-dry and rough. According to Figure 6 , the circles of correlation on the first two axes show a positive correlation between soft and silky with a value of 0.884 on a level of significance alpha equal to 0.005 . Indeed, both attributes are kept because they are used very frequently in the hygienic product industry. In order to permit panelist recognition of the difference between these two terms, we have rectified the evaluation methods and the definition of both attributes. Following these analyzes, we have rectified the form used for the evaluation. Indeed, on this questionnaire the selected references as well as the new evaluation method for each descriptor were indicated. Furthermore, the order of evaluation have been changed. Thus the descriptors characterizing surface and physical touch will be evaluated first according to the evaluation method, while those for characterizing the dynamic touch will be evaluated last.

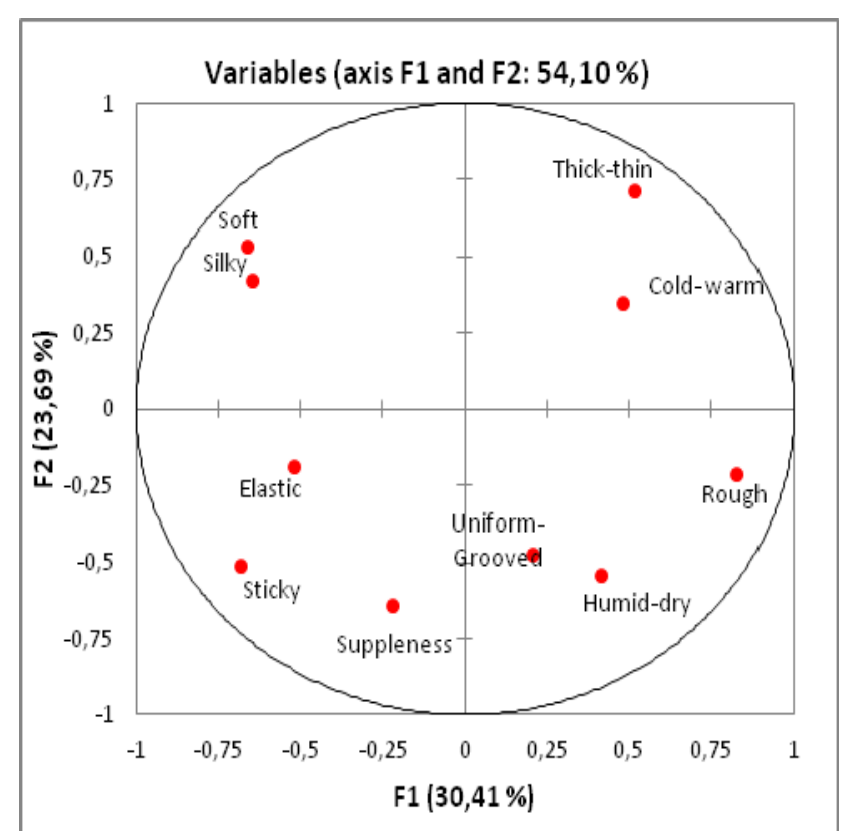

Figure 6.: Circle of correlation after initiation training sessions. 


\subsection{Establishment of a manual guide of procedures and tactile reference frame}

Taking advantage of the previous sensory experience in textile and more precisely the training of an industrial touch panel for woven fabric. Based on the weaknesses and missing points, a company-specific dashboard technique were developed. Referring to the procedures described in literature also by panel consensus. It is very important to take into consideration the types of samples to be tested while avoiding gestures that can cause panel fatigue. After the initiation-sessions a well-defined assessment techniques for each attributes were set and summarized in Table 9. The tactile sense is devised into 10 descriptors that influence the nature of touch. In fact, they are associated with the type of touch and with the type of the gestures adopted presented in previous section in. It can be used also as a memory help tool during the sensory evaluation. Each sample was assessed in terms of the following basic tactile descriptors:

- Temperature (from cold to warm: to hold the suspended sample with full hand)
- Dryness: (from humid to dry: to hold the suspended sample with full hand)

- Thickness: (from thick to thin: to estimate Thickness with Thumb and Index finger)

- Stickiness (force required to separate fingers from surface: to Estimate the presence of a fatty film between the palm of the hand and the surface.),

- Uniformity: (from uniform to groove: to judge the presence of the reliefs or with the nails and the end of thumb.

- Suppleness: (capability of being flexed without breaking; able to be turned, bowed, or twisted: Handle and wrinkle the sample with both hands)

- Roughness (presence of relief, particles, harshness... etc: to slide the flat hand over fabric).

- Elasticity: (resistance against deformation, capacity of stretching: Pull on the sides of samples with both hands)

- Softness: (smooth and agreeable to the touch; not rough or coarse: to graze with the palm of your hand and your fingers)

- Silkiness: (compared to feel like silk when touched: rub gently between your fingers and thumb)

Table 9. Assessment techniques for the retained attributes.

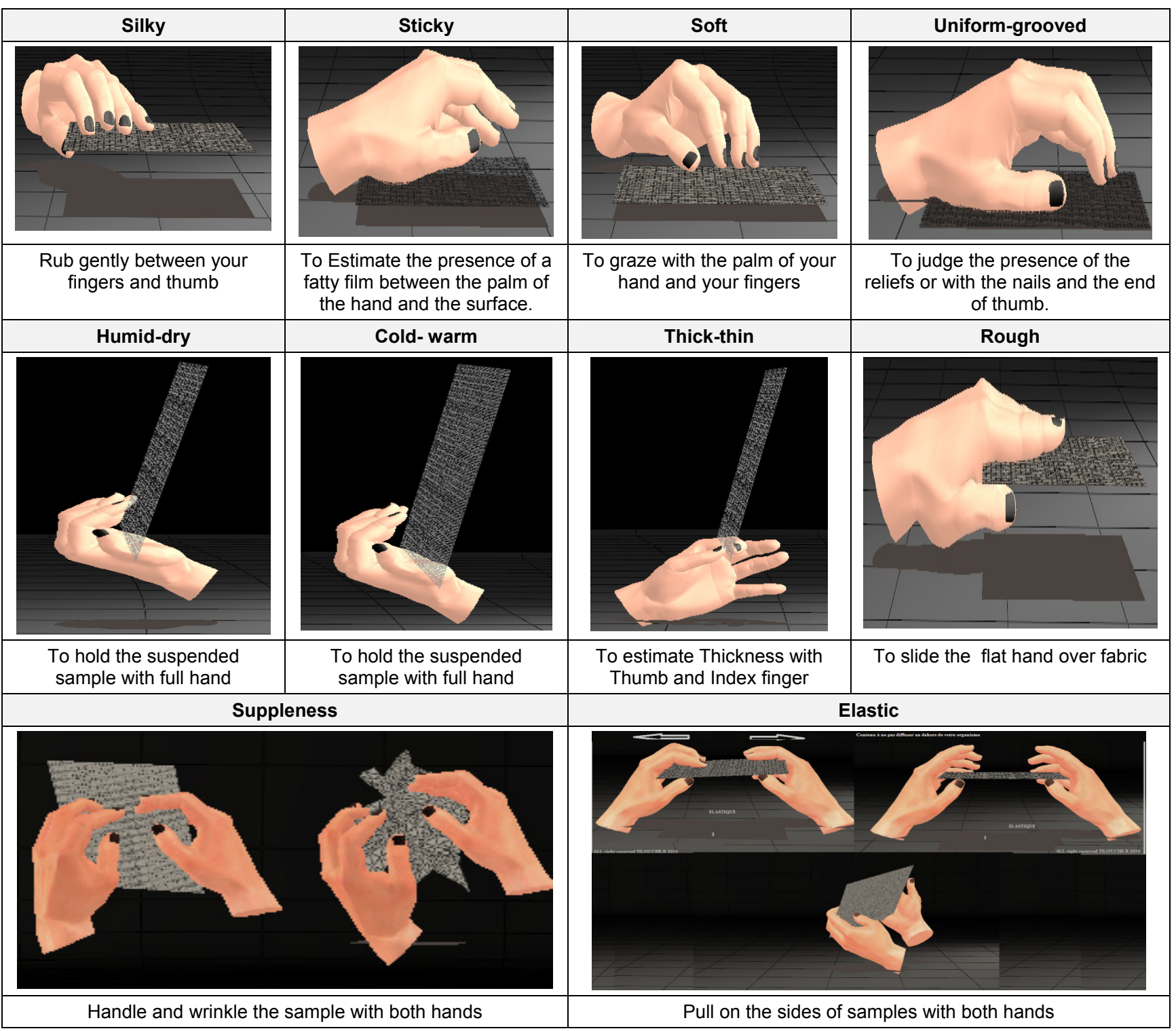




\section{CONCLUSION}

Comfort in companies has become a must-have criterion in the product; it is no longer an option. Especially for the companies of hygienic products that deal with customers in perpetual exigency in term of comfort and quality. Accordingly, testing area location were carefully selected, test booth, panelists, tested samples and descriptors. A practical list of descriptors were established for tactile sensory analysis adapted to hygienic product. Sixty attributes were generated by three different methods. A preliminary qualitative and quantitative reduction have been conducted that led to 15 attributes being retained as they showed to be relevant for describing nonwoven for hygienic product. During the first training session, an analysis enabled having 14 attributes. Finally, by group consensus, for each attribute an assessment method and a negative and positive reference were fixed. After those sessions, panelists are able to properly use a scale notation from 0 to 10.
After several training sessions, the panelist acquired some competence in standardized tactile sensory evaluation. To realize a sensory profile, subjects use the manual guide of procedures to have consistent performance and manage to differentiate correctly differences between samples. To reach this stage, these skilled panelists attended repetitive training sessions, in which the presentation of the samples was repetitive. The ultimate objective of these training sessions is to have a group of experts able to accurately assess the touch of the textile fabrics. This will be the aim of further work witch deals with training and panel performance control.

\section{ACKNOWLEDGEMENT}

We would like to express our sincere gratitude to Mr. Khaled KALLEL \& Mrs LAABIDI Yosra Senior Managers in R\&D department in SANCELLA Ksibat el Mediouni for supporting this research. We thank all panel members who provided and invested from their time and greatly assisted for the panel establishment.

\section{REFERENCES}

1. Teko H.T. and Bapes Y., 2010, «Sociology,» [Online]. Available: http://sociologies.revues.org/3204. [Access le 25-09-2015].

2. Wrońska B. and Grębosz M., 2013 «Sensory Impact on the Purchase of Textile Products,» fibers and textile in eastern europe, vol. 21 , $\mathrm{n}^{\circ} 199$, pp. 8-12.

3. Depeldt F., 2009, Sensory anlysis: Methodological manual, 3 éd., France: lavoisier.

4. ISO 5492, 1992-Revised 2012 «Sensory analysis -- Vocabulary,» International Organization for Standardization France.

5. Bernard A.B., 2015, «Factors Affecting Human Comfort Response to Garments,» Life Science Journal, Raleigh, North Carolina, vol. 12, $\mathrm{n}^{\circ} \% 16$, pp. 129134

6. Vibert J.F. and al, , 2011, Neurophysiology: From physiology to functional exploration, 2 éd., vol. 2, Elsevier Masson, p. 280.

7. Wiertz P.,2016, «fact sheet disposable baby diapers,» [On line]. [Access :20-6-2016], Available: www.edana.org.

8. Yokura H. and al, 2012, «Objective hand measurement of nonwoven fabricused for topsheet layer,» Faculty of education, shiga university \& Nara women's university, pp. 703-712.

9. Yokura H. and Sukigra S., 2010, «Evaluation of the Wetness of Pantiliners,» Textile reaserch journal vol. 80, $\mathrm{n}^{\circ} 116$,

10. Hallab N. and al, 2013 «Training and control of performance of a tactile sensory panel,» Journal of Applied Science, vol. 13, $n^{\circ} 13$, pp. 366-376

11. Agarwal G. and Koehl L., 2011, «Sensory Study of Knitted Fabrics that Have Gone Through Washing Cycles with Domestic Softener. Part I: Establishment of a Panel and Assessment Thereof,» fibres \& textiles in Eastern Europe, vol. 19, $n^{\circ} 13(86)$

12. NF ISO 13300-1, 2006, Sensory analysis -- General guidance for the staff of a sensory evaluation laboratory -- Part 1: Staff responsibilities, 1 (Monolingue) éd., International Organization for Standardization.

13. NF EN ISO139, 1992 Reapproved 2005, «Textiles - Standard atmospheres for conditioning and testing:,», International Organization for Standardization.

14. NF ISO 8589, 2010, Sensory analysis - General guidance for the design of test rooms, International Organization for Standardization.

15. ISO 13299, 2003- Revised 2010, «Sensory analysis -- Methodology -- General guidance for establishing a sensory profile,» International Organization for Standardization.

16. Osborn A., 2009, Unlocking Your Creative Power: How to Use Your Imagination to Brighten Life, to Get Ahead, Broché éd., H. Books, Éd., New York: Charles Scribners \& Sons, p. 64.

17. ISO 11035, 1994-Revised 2010, «Sensory analysis -- identification and selection of descriptors for establishing a sensory profile by a multidimentioanl profile,» ISO/TC 34/SC 12, International Organization for Standardization..

18. Deladreire J.L. and al, , 2014,Mind mapping , organizing your idea, 3 éd., DUNOD, Éd., Professinal efficacity, p. 208.

19. Triplett J., 2006, Manual of Hedonic Indices and Quality Adjustments in Price Indices: Special Application to Information and Communication Technology Products, OCDE éd., OECD Publishing.

20. Lebvre A. and Bassereau J.F., «Sensory analysis, a measurement method at the service of the design actors: its advantages, its limits, its ways of improvement: Packaging application,» pp. 3-11, 2003.

21. Mithat Ç. And al, 2011, «A scale development study to evaluate the physical comfort of denim jeans,» TEKSTIL ve KONFEKSiYON, vol. $21, \mathrm{n}^{\circ}$ 11, pp. $77-$ 81 